\title{
Impact of Delivery Service on Retail Business
}

\author{
Benyada Laotanathaworn ${ }^{1}$, Suppamas Rattanapipat ${ }^{2}$ \\ ${ }^{1,2}$ Faculty Management Science, Yala Rajabhat University \\ ${ }^{1}$ lao.benyada@gmail.com, ${ }^{2}$ suppamas.ratta@gmail.com
}

\begin{abstract}
The purpose of this research is to 1) to study customer satisfaction levels toward the retail delivery business of convenience stores in Yala Province 2) study the effects of the delivery services on retails stores in Yala Province. This is quantitative research employing a questionnaire as a tool to collect data from 400 samples of customers using the delivery services in Mueang District, Yala Province. From the descriptive statistics analysis, the result identifies the profiles of the delivery service customers as follows. 1) $69 \%$ female 2) between $60 \%$ years old 3 ) 10,001-20,000 Baht income 4) less than 5 times per week 5) free of charge delivery 60\% 6) less than 1,000 Baht spent per month. Results indicated that opinions of customers toward the delivery service of retail business in Yala is highest can be explained as follows. 1) The convenience of gaining services is at the high level with the average value at 4.37 2) The reliability on the service quality is at the high level with the average value at 3.943 ) The speed of delivery is at the high level with the average value at 3.624 ) The accuracy score is high at The accurate quantity of the goods orders with the average value at 3.57, and 5) The satisfaction on the rider service is at the high level with the average value at 3.45. Statistically, the hypothesis test indicates that the difference in the individual profiles such as gender, age, marital status, education level and profession shows an insignificant impact rate at 0.05 on the opinion toward the retail delivery business.
\end{abstract}

Keywords

Retail Business, Delivery Service

Article Received: 10 August 2020, Revised: 25 October 2020, Accepted: 18 November 2020

\section{Introduction}

Retail is a business that has been with Thai people for a very long time. It directly involves the consumers or end users as they purchase the products or services for consumption purposes, not for sales or reselling. In our daily life we see retails all the time from the very moment we step out from our home. There are retail stores everywhere at every corner of the street, from small retail shops such as street vendors to large retail stores such as shopping malls, shopping centers or convenience stores. The retail business is one of the most important businesses to the consumers as it acts as the center of all the goods required by the consumers with various needs depending on each individual, and as a hub providing information on the needs to the manufacturers, and as a key to the economic system of Thailand, as it delivers the goods to the consumers. The retail business shares $18 \%$ in the country's economic system [1]. The retail business can be divided into two main categories that are the traditional trade and modern trade. [2] In 2018 - 2020 the modern trade grows constantly as a result of the ongoing city expansion, covering the consumers in Bangkok and major cities, supporting business opportunities from the changes [3]. Therefore the retail business has played an important role in Thailand's trade. Modern trade can be divided into 5 main categories that are: 1. Department Stores 2. Discount Stores (Hypermarket/Cash \& Carry) 3. Supermarket 4. Convenience Stores 5. Specialized Stores. [4] However, in 2020 the retail business saw a steep decline due to the COVID-19 pandemic reducing the purchasing power of the people in the country, including the absence of foreign tourists. The effects impact the overall revenue of the business in 2020 by $-10.0 \%$ up to $-13.6 \%$ when compared to 2019. [5] Despite the adverse effects of COVID-19 in the retail business, but convenience stores still continue to gain revenue and expand new branches.
Moreover, the operators gradually adopt online shopping platforms to increase revenue in the e-commerce segment that is growing rapidly. The foregoing factors may increase the competition in the business while globalization with digital technology continues to change consumer behavior. The business will have to adapt itself to the rapid changes, adjust the commercial strategy, providing new services to be able to distinguish itself and increase the competitiveness to keep drawing customers in the long run. Thus customer services have become a vital part of all segments of the business because they are a tool to create a distinction and competitiveness. In addition, quality customer services will create a bond with the customers and enhance the value of the business in the long run. Today, one of the key services in the retail business and other business is product delivery because it is more convenient to the customers where they have access to a variety of goods, due the customer behavior that has changed significantly from the past as now they demand to receive the products immediately or as quickly as possible. And if the vendor is unable to meet this requirement, the customers will receive the service or product from other vendors who have similar quality but able to respond faster. Therefore this research studies to find the effects of the product delivery toward the customers in the online business to improve the service to directly meet the demand of the customers, and to increase revenue for the retail business in the future.

\section{Research Objectives}

1) To study the satisfaction level of the retail product delivery of the convenience stores in Yala Province.

2) To study the impacts of the retail product delivery of the convenience stores in Yala Province. 


\section{Scope Of Research}

\section{1.population \& sample scope}

The study population is the delivery customers of the convenience stores in Mueang District, Yala Province. The calculated number of samples is 400 units from the Convenience Sampling method [2].

\section{Variables Scope}

2.1 Independent Variables: Individual variables such as gender, age, income level and education.

2.2 The study of the behavior of the delivery customers of the convenience stores in Mueang District, Yala Province in relation to the order frequency, reasons for choosing the delivery service, and the monthly spending rate.

\section{Dependent Variables:}

3.1 The study of the concept of the delivery customers of the convenience stores in Mueang District, Yala Province in relation to the convenience, delivery duration, delivery accuracy, satisfaction toward the riders, and reliability.

\section{Methods}

This research is quantitative and employs a questionnaire as a tool to collect data from 400 samples of customers using the delivery services in Mueang District, Yala Province. A questionnaire was given to the customers when they entered the convenience store. Customers filled out the questionnaire and give it back to research assistant. Quantitative data were analyzed using descriptive statistical analysis such as Frequency Distribution, and percentage finding before presenting in the form of an essay article.

\section{Results}

\section{Results indicated that}

A. Gender of the samples: $69 \%$ Female, $31 \%$ Male, this indicates that the majority of the delivery customers of the convenience stores in Mueang District, Yala Province is female.

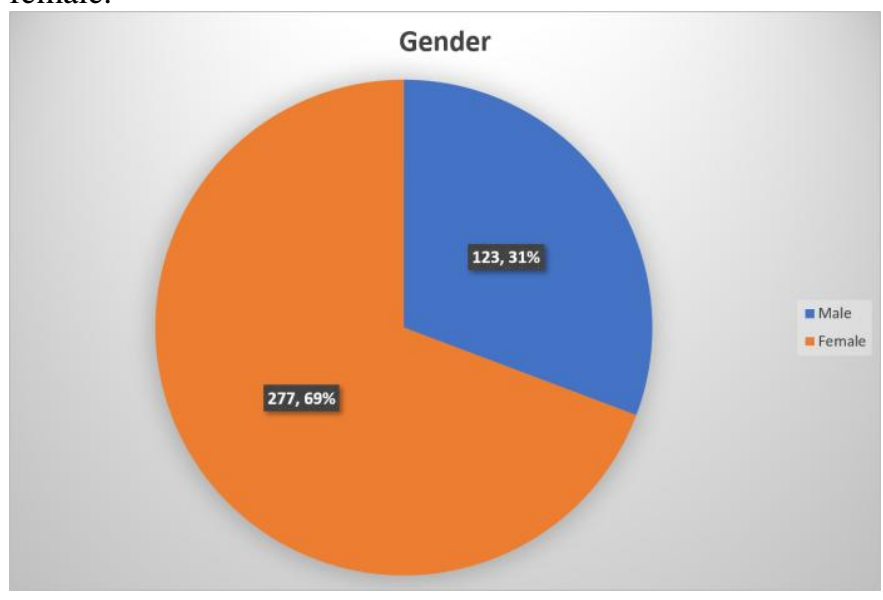

B. Age: $13 \%$ below 15 years old, 60\% 16-30 years old, $19 \% 31-50$ years old, and $8 \%$ older than 50 years, the majority of the delivery customers of the convenience stores in Mueang District, Yala Province is $16-30$ years old.

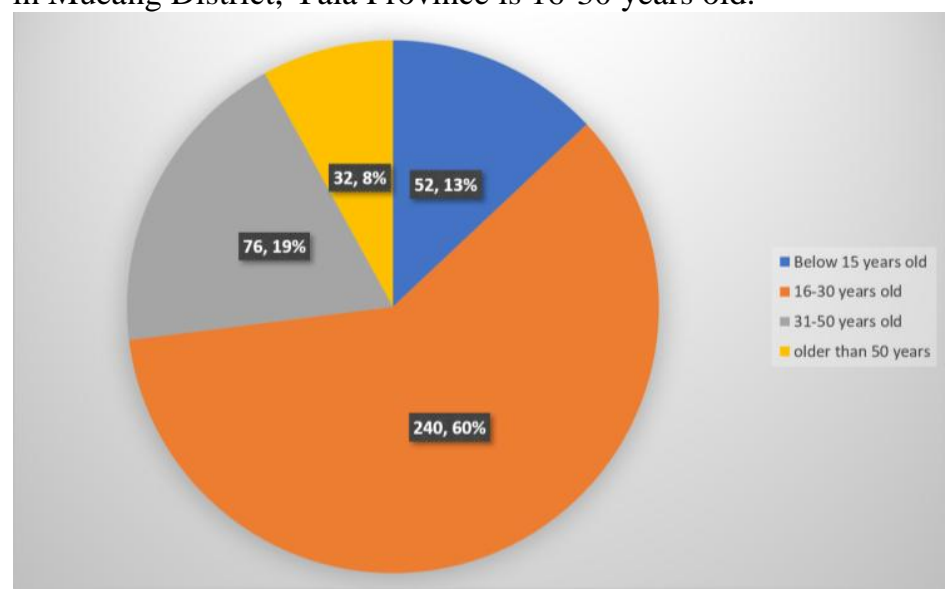

C. Income: $8 . \%$ below 10,000 Baht, 55\% 10,00020,000 Baht, $30 \%$ 20,001-30,000 Baht, and 7\% over 30,000 Baht, the majority of the delivery customers of the convenience stores in Mueang District, Yala Province has an income of 10,001-20,000 Baht.

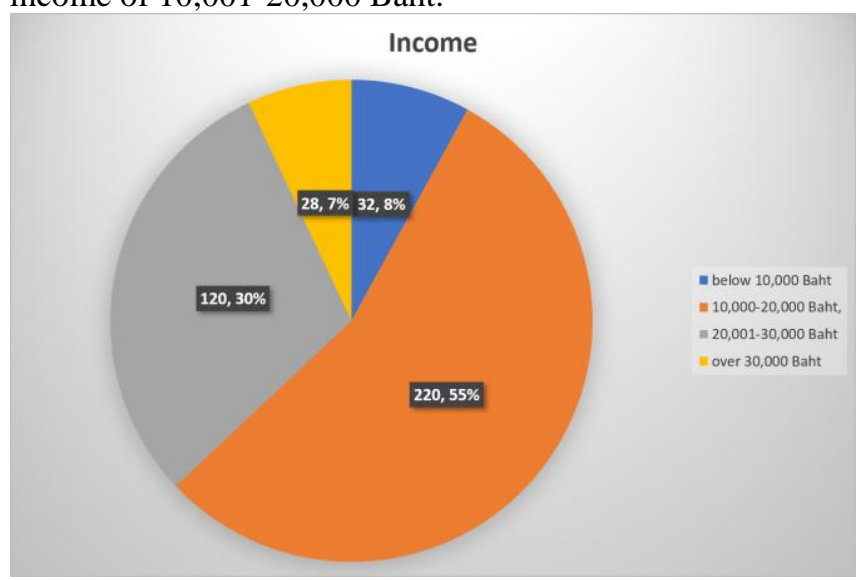

D. Frequency: $15 . \%$ regularly, $24 \%$ weekly, $46 \%$ less than 5 times a week, $5 \%$ less than 10 times a month, $10 \%$ never, the majority of the delivery customers of the convenience stores in Mueang District, Yala Province uses the delivery service less than 5 times a week.

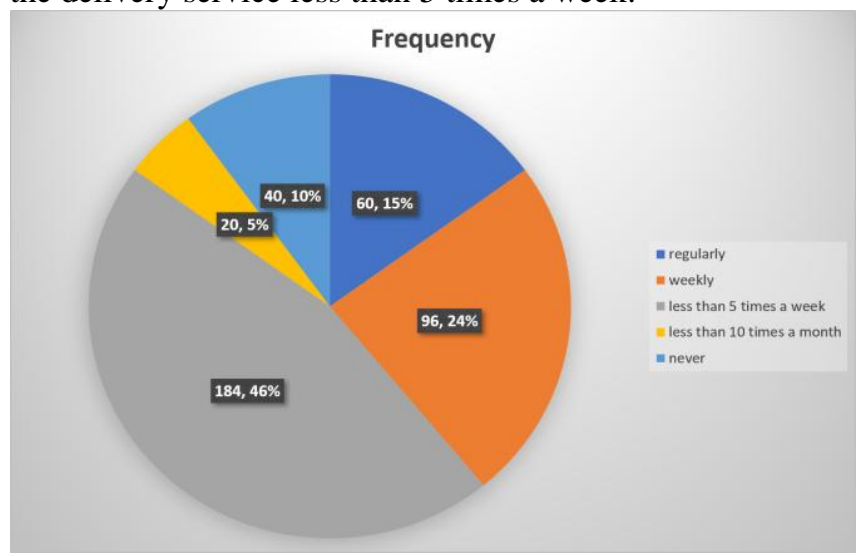

E. Reason for using the delivery service from the convenience stores in Mueang District, Yala Province: $47 \%$ free service, $15 \%$ convenience, $35 \%$ rush hours, $3 \%$ 
others, the majority of the delivery customers of the convenience stores in Mueang District, Yala Province uses the service because it is free, and use it during the rush hours.

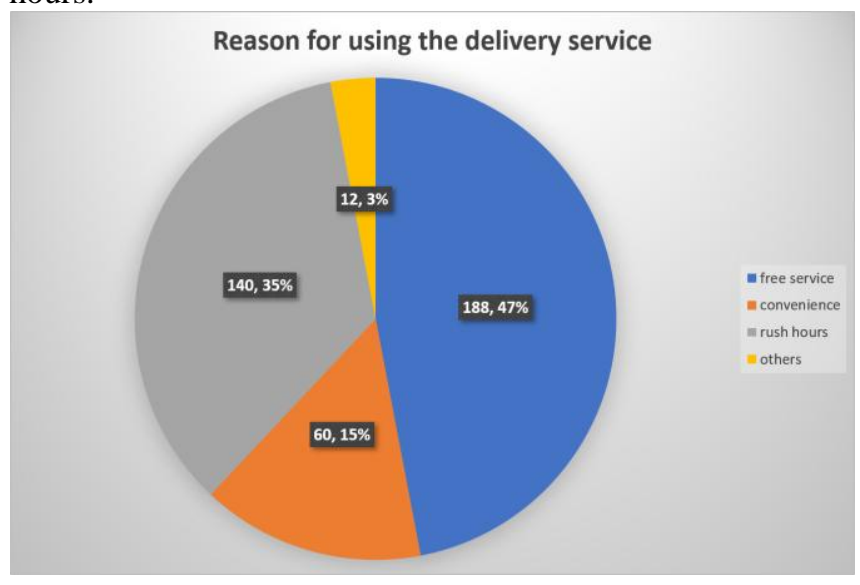

F. Spending per month for the delivery service: $47 \%$ below 1,000 Baht, $15 \%$ 1,001-2,000 Baht, $35 \%$ 2,0013,000 Baht, and $3 \%$ over 3,000 Baht, the majority of the delivery customers of the convenience stores in Mueang District, Yala Province spends less than 1,000 Baht per month for the delivery service.

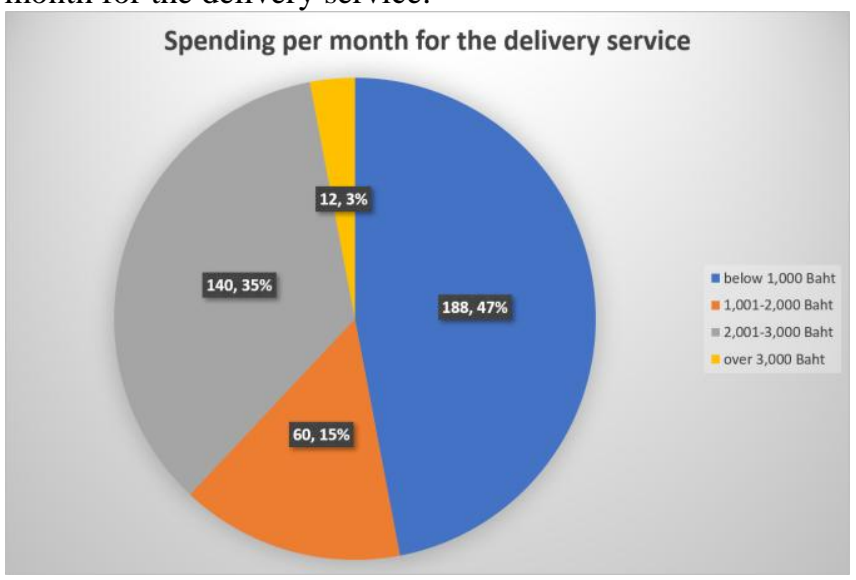

G. Concept of the majority of the delivery customers of the convenience stores in Mueang District, Yala Province:

\begin{tabular}{|l|c|}
\hline \multicolumn{1}{|c|}{ Category } & Satisfaction \\
\hline $\begin{array}{l}\text { The convenience of gaining } \\
\text { services }\end{array}$ & 4.37 \\
\hline The speed of delivery & 3.62 \\
\hline $\begin{array}{l}\text { The accurate quantity of the } \\
\text { goods orders }\end{array}$ & 3.57 \\
\hline $\begin{array}{l}\text { The satisfaction on the rider } \\
\text { service }\end{array}$ & 3.45 \\
\hline $\begin{array}{l}\text { The reliability on the service } \\
\text { quality }\end{array}$ & 3.94 \\
\hline
\end{tabular}

Table 1 : opinions of customers toward the delivery service of retail business in Yala

The opinions of customers toward delivery service of the retail business in Yala can be explained as follows. 1) The convenience of gaining services is at the high level with the average value at 4.37 2) The reliability on the service quality is at the high level with the average value at 3.94 3) The speed of delivery is at the high level with the average value at 3.624 ) The accuracy score is high at The accurate quantity of the goods orders with the average value at 3.57, and 5) The satisfaction on the rider service is at the high level with the average value at 3.45 . Statistically, the hypothesis test indicates that the difference in the individual profiles such as gender, age, marital status, education level and profession shows an insignificant impact rate at 0.05 on the opinion toward the retail delivery business.

\section{Recommendations}

The researcher's suggestion from the result as below:

1. The convenience stores providing delivery services in Mueang District, Yala Province should promote their products and services to women because the majority of the customers is female.

2. The free delivery service has a strong influence on the decision of the customers. It should continue to be free to attract more customers and increase the number of customers in the future.

3. The customer group who order the delivery service on a daily basis is $16-30$ years old due to the convenience. There should be more promotions for the 16-30 years old group.

4. Increase advertisements, publications, or promotions in the rush hours, morning, and evening to attract more customers during the rush hours, and secure regular customers during the hours as this is the second strongest reason for using the service.

5. There should be a promotion to increase the order frequency as the frequency is less than 5 times a week which links to the revenue of the delivery service. If the frequency is increased, the revenue should be increased also.

6. The service standard of the delivery riders should be improved to increase customer satisfaction which will lead the customers to return.

\section{Conclusion}

The impacts of the delivery service of the convenience stores in Mueang District, Yala Province are positive because the customer satisfaction score is high, apart from the high demand during the COVID-19 situation. The convenience of gaining services obtains the highest customer satisfaction score. However, the research result indicates that the customers are satisfied with The convenience of gaining services, The speed of delivery, The accurate quantity of the goods orders score is high while The satisfaction on the rider service and The reliability on the service quality still fall behind. If the business can improve all aspects of the delivery service to fully satisfy the customers, the delivery service should be able to be expanded sales revenue in the future. 


\section{References}

[1] Bank of Thailand, "Business Outlook Report Quarter 3/2020, from https://www.bot.or.th/Thai/MonetaryPolic $\mathrm{y}$ /EconomicConditions/BLP/BLP_TH_Q3 2020.pdf

[2] Michael Levy and Barton Weitz, Retailing Management 10th Edition, McGraw-Hill, 2019.

[3] Krungsri Bank, Industry Outlook 2019 2021:Modern Trade, from https://www.krungsri.com/en/research/ industry/industry-outlook/WholesaleRetail/Modern-Trade/IO/io-modern-trade20

[4] Thailand Development Institute, Study of the wholesale business to prepare for drafting Laws of Wholesale Retail Business Suitable for Thailand, Department of Internal Trade, 2017.

[5] Gsbresearch, Modern Trade Business, from https://www. gsbresearch.or.th/wpcontent/uploads/2020/03/IN_trade_9_62_d etail.pdf 